\title{
Animal models of atherosclerosis (Review)
}

\author{
YEE TING LEE ${ }^{1}$, VICTORIA LAXTON ${ }^{2}$, HIU YU LIN ${ }^{1}$, YIN WAH FIONA CHAN ${ }^{3}$, \\ SOPHIA FITZGERALD-SMITH ${ }^{4}$, TSZ LING OLIVIA TO ${ }^{5}$, BRYAN P YAN ${ }^{5,6}$, TONG LIU $^{7}$ and GARY TSE ${ }^{5,8}$
${ }^{1}$ School of Biomedical Sciences, Li Ka Shing Faculty of Medicine, University of Hong Kong, Hong Kong, SAR, P.R. China;
${ }^{2}$ Intensive Care Department, Royal Brompton and Harefield NHS Trust, London SW3 6NP;
${ }^{3}$ School of Biological Sciences, University of Cambridge, Cambridge CB2 1AG, ${ }^{4}$ Faculty of Medicine, University of Bristol, Bristol BS8 1TH, UK; ${ }^{5}$ Department of Medicine and Therapeutics, Chinese University of Hong Kong,
Hong Kong SAR, P.R. China; ${ }^{6}$ Department of Epidemiology and Preventive Medicine, Monash University, Melbourne, Victoria 3004, Australia; ${ }^{7}$ Tianjin Key Laboratory of Ionic-Molecular Function of Cardiovascular disease, Department of Cardiology, Tianjin Institute of Cardiology, Second Hospital of Tianjin Medical University, Tianjin 300211,
${ }^{8} \mathrm{Li}$ Ka Shing Institute of Health Sciences, Chinese University of Hong Kong, Hong Kong, SAR, P.R. China

Received October 12, 2016; Accepted December 14, 2016

DOI: $10.3892 /$ br.2017.843

\begin{abstract}
Atherosclerosis is a significant cause of morbidity and mortality globally. Many animal models have been developed to study atherosclerosis, and permit experimental conditions, diet and environmental risk factors to be carefully controlled. Pathophysiological changes can be produced using genetic or pharmacological means to study the harmful consequences of different interventions. Experiments using such models have elucidated its molecular and pathophysiological mechanisms, and provided platforms for pharmacological development. Different models have their own advantages and disadvantages, and can be used to answer different research questions. In the present review article, different species of atherosclerosis models are outlined, with discussions on the practicality of their use for experimentation.
\end{abstract}

\section{Contents}

1. Introduction

2. Animal models of atherosclerosis

3. Concluding remarks

\section{Introduction}

Atherosclerosis is an autoimmune condition characterized by the development of complex atherosclerotic plaques, leading to hardening and narrowing of the arterial lumen. Chronic exposure

Correspondence to: Professor Gary Tse, Department of Medicine and Therapeutics, Chinese University of Hong Kong, 30-32 Ngan Shing Street, Shatin, Hong Kong, SAR, P.R. China

E-mail: tseg@cuhk.edu.hk

Key words: animal models, rabbit, porcine, primate, atherosclerosis to cardiovascular risk factors, such as hyperlipidemia, hypertension, smoking, male gender and diabetes, can increase the rate and severity of atherosclerosis. Among the different risk factors, increased plasma low-density lipoprotein (LDL) level has been identified as the most significant, which alone is sufficient to produce atherosclerosis in monogenetic hyperlipidemia disorders, such as familial hypercholesterolemia (1). In individuals with normal LDL levels, other factors are responsible for the development and progression of atherosclerosis $(2,3)$. However, these risk factors are rather insignificant in individuals with low LDL levels, who are unlikely to develop atherosclerosis irrespective of the presence of additional risk factors (4).

Excess LDL in plasma accumulates in the sub-endothelial space of the arterial wall, undergoing oxidation to become oxidized LDL (oxLDL). This in turn, triggers an inflammatory response, thereby inducing the expression of a number of different molecules, such as vascular cell adhesion molecule-1, E-selectin and P-selectin in the endothelium (5). This response provides the necessary conditions for chemotaxis, where blood cells are recruited into the injured arterial wall (6). Monocytes are the most prominent cell type involved (7). After entry into the tunica intima, monocytes undergo differentiation into macrophages, which take up oxLDL to become foam cells (8). Foam cells function as antigen-presenting cells, and activate circulating monocytes and T-cells (9). They also secrete mediators to further perpetuate inflammation, and stimulate the migration of smooth muscle cells from the tunica media into sub-endothelial space (10). Mediated by platelet-derived growth factor, the smooth muscle cells exhibit abnormally high proliferation rates and secrete extracellular matrix proteins that contribute to fibrous cap formation (11). The fibrous cap protects the core of the plaque from circulating blood cells, especially platelets responsible for the thrombosis associated with rupture plaques. This maladaptive non-resolving inflammation is the driving force of atherosclerotic plaque development (12). SMCs from different regions of the microvasculature have different developmental origins (13), which can contribute to site-specific atherosclerotic responses (14). 
During plaque evolution, macrophages proliferate, undergo apoptosis and efferocytosis $(15,16)$. Apoptotic cells may be removed, leading to lesion size reduction, or may accumulate and be subjected to secondary necrosis, producing the necrotic core characteristic of advance plaques. Accumulation of apoptotic bodies may enhance the plaque instability by triggering inflammation. While foam cells are the most abundant leukocytes within the atherosclerotic lesions, other cell types, including neutrophils, mast cells, T-lymphocytes and B-lymphocytes are also involved in atherogenesis $(17,18)$. Although these cells contribute little in mass to the lesions, they can secrete different signalling proteins that regulate other cells or components within the plaques (19-21).

Plaque rupture is responsible for the adverse clinical consequences of ischaemia in cerebrovascular accidents, myocardial infarction and heart failure, producing significant morbidity and mortality in affected patients. In advanced stages of atherosclerosis, rupture of vulnerable plaques exposes their thrombogenic compounds, producing luminal thrombosis. Destabilization of plaques into a vulnerable state is in part mediated by macrophage-derived proteases, such as metalloproteases; however, the precise mechanisms remain incompletely characterized (22).

\section{Animal models of atherosclerosis}

In 1908, Ignatowski provided the first experimental demonstrations that atherosclerosis can be induced in laboratory animals. He fed rabbits a protein-rich diet (mainly meat, milk, and egg yolk), which led to the formation of atherosclerotic lesions in the aortic wall. Since then, a number of species, such as rabbits, mice, rats, guinea pigs, hamsters, birds, dogs and non-human primates, have been developed. Despite differences between the animal models, a common finding is the necessary condition of hypercholesterolaemia in plaque development. Animal models have been extensively used for the study of human cardiovascular diseases (23-41). In the present review, we review rabbit, porcine and non-primate models of atherosclerosis, together with their advantages and disadvantages (Table I).

Rabbit. Rabbit is the first animal model developed for atherosclerosis research, leading to the identification of the crucial role of elevated plasma cholesterol in atherogenesis. It served as the mainstay of pre-clinical model until genetically modified mouse models became widely available.

New Zealand White (NZW) strain. The most common strain is the NZW, in which the roles of lipoproteins of differing sizes on atherosclerosis were examined. For example, atherosclerosis was unexpectedly inhibited in an alloxan-induced diabetes rabbit model, explicably by the accumulation of large triglyceride-rich lipoprotein ( $>75 \mathrm{~mm}$ diameter), to which the vascular wall has limited permeability $(42,43)$. However, NZW rabbits show high biological variability with respect to individual responsiveness to dietary cholesterol and the lesion morphology varies significantly depending on the cholesterol content of the diet (44). This strain is not prone to atherosclerotic risk due to its low plasma cholesterol level of $50 \mathrm{mg} / \mathrm{dl}$ when exposed to standard diet. The induction of vascular lesion in NZW rabbits generally requires feeding of a high cholesterol diet (from 0.2 to $2 \%$ cholesterol) which increases plasma cholesterol level by $\leq 8$-fold and leads to the formation of foam cells-enriched fatty streaks in several vascular regions, especially the aortic arch and the thoracic aorta (45). For complex atherosclerotic plaques with lipid core surrounded by smooth muscle cells to develop, a long period of cholesterol feeding, from six months to several years, is required. The disadvantage of this diet is its hepatic toxicity, which increases mortality.

Genetically modified rabbits. Due to the noxious side effects of the high-fat diet, genetically modified rabbits have been developed to produce spontaneous atherosclerotic lesions. For example, Watanabe hereditary hypercholesterolemic rabbit (WHHL), a LDLR-deficient model, was used by Buja et al, who identified LDL as the lipoprotein underlying human familial hypercholesterolemia (46). The advantage of this WHHL model is that the morphology of lesions and lipid metabolism are largely similar to those observed in humans. When WHHL rabbit is fed with $1 \%$ cholesterol for 12 months, the atherosclerotic plaques resemble those seen in homozygous familial hypercholesterolemia patients $(46,47)$, with areas of necrosis, cholesterol clefts and calcification (48), with foam cells originating from smooth muscle cells. Furthermore, WHHL rabbits share the same gender predisposition patterns, with males being more prone to coronary atherosclerosis (49).

Advantages and disadvantages of rabbit models. Rabbits share the same advantages with mice with their small size and hence ease in maintenance, high availability and low economical cost. They are frequently preferred because of similar lipoprotein metabolism to humans. With the expression of CETP, the predominant lipoprotein in rabbit is LDL (45). Rabbits are sensitive to dietary cholesterol overload, demonstrating subsequent hyperlipidemia without the need of the toxic high cholesterol diet. Since rabbits are larger than mice, catheter-based procedure and non-invasive imaging can be used for experimental interrogation. Some important differences are that the frequent sites of atherosclerotic lesions in rabbits are the aortic arch and descending thoracic aorta, whereas those in humans are the coronary arteries and the abdominal aorta (45). Nevertheless, application of an ameroid constrictor to induce arterial stenosis in rabbit coronary arteries led to intimal proliferation together with eccentric narrowing 4 weeks later (Fig. 1) (30).

Porcine. The different porcine models can broadly be divided into wild-type or genetically modified models.

Wild-type pig models. Rapacz pig is a wild-type model with a natural mutation in $A p o B$ and $L D L R$ genes, which were produced by selective breeding of pigs with high cholesterol by Davis et al (50). Within 2-4 years on a normal diet, these pigs developed increased hypercholesterolemia, with LDL as the main circulating lipoprotein, associated with the development of coronary atherosclerosis. A mini-pig model bearing the same gene mutation but with lower cost, the hypercholesterolemia Bretoncelles Meishan (FBM) pigs, was subsequently made available (51). The diabetic 
Table I. Models of atherosclerosis with their advantages and disadvantages.

Animal experimental models

\section{Rabbits}

Advantages

Similar lipid metabolism with human

Similar morpology of lesion development

Low cost for maintenance

High availability

Larger artery allow clinical evaluation: Ultrasound and MRI can be applied to determine plaque composition and its vulnerability

Low cost of maintenance due to its small size

Disadvantages

Not always responsive to dietary cholesterol

Different cardiovascular physiology with human: HDL as the predominant plasma lipoprotein, absence of Apo AII, low hepatic lipase activity

Low hepatic lipase acitivity leads to hepatotoxicity following prolonged cholesterol feeding

Plaque lesion dissimilar with human: foam cells with more fatty streak and macrophage rich, advanced lesion (e.g., Fibrosis and haemorrhage and ulceration) are not seen

Different predilection site: Atherosclerotic plaque preferentially deposited in aorta, iliac arteries

Porcine

\section{Advantages}

Similar haemodynamics and pathogenesis to humans: Lesion location, morphology and content

Similar heart size and cardiovascular anatomy

Similar lipid metabolism, except for Apo II deficiency in porcine

Highly defined genotypes for genetic manipulation

Minipig version offer option with lower cost

Unlike mouse and rabbit, it can spontaneously develop atherosclerosis with an accelrated rate when fed with atherogenic diet

Easier to carry out imaging, e.g., Ultrasound, CT and MRI compared to smaller species

Disadvantages

Toxic diet needed for induction of atherosclerosis

Large in size, which limits its practical use

Non-human primates

\section{Advantages}

Similar cardiac anatomy: Same predilection site for atherosclerosis

Similar cardiac physiology: Comparable lipid metabolism and advanced atherosclerotic lesion found

Closest phylogenetic relationship with human

Highest resemblance to human atherosclerotic clinical condition

Susceptible to spontaneous atherosclerosis

Similar omnivorous diet

Disadvantages

High cost for purchase and maintenance

Long lifespan and hence long period of time needed for induction of atherosclerosis

Significant ethical concern

Large size with difficulty of management

Low availability

hypercholesterolemic wild-type pig can provide a humanoid model for investigations. An example is the type I diabetes model produced by intravenous streptozotocin injection, which has been used to destroy $>80 \%$ of pancreatic $\beta$-cells in Yorkshire pigs (52). Its combination with a high cholesterol diet used to induce hypercholesterolemia increased atherosclerotic risk by 2-fold, compared with hypercholesterolemia alone. Diabetic Yorkshire pigs demonstrated an accelerated rate of atherosclerotic lesion development in the aorta, coronary and femoral arteries (53). The lesions developed exhibit human-like 


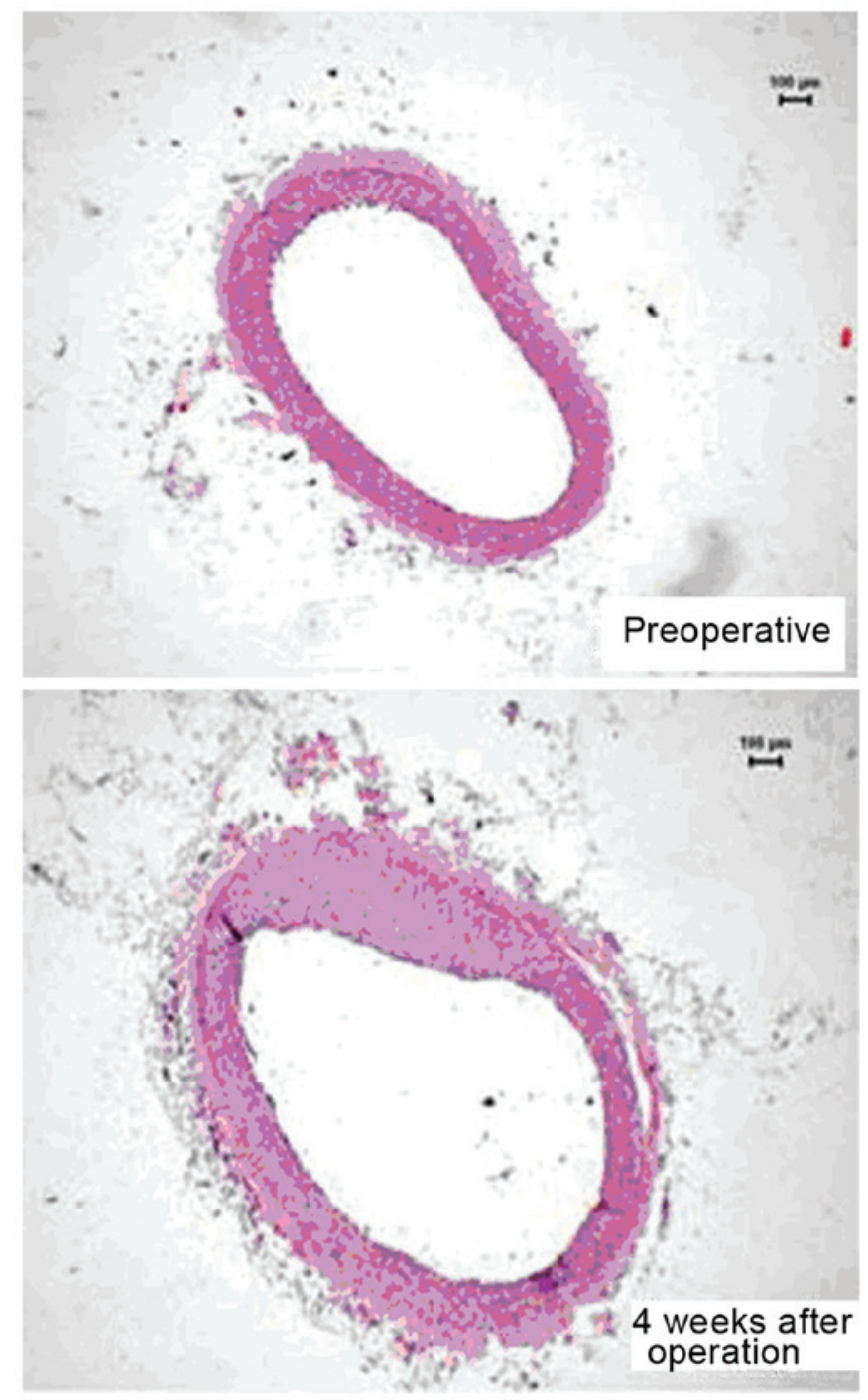

Figure 1. A cross-sectional image of a coronary artery in a rabbit model before (top) and 4 weeks after application of an ameroid constrictor to induce arterial stenosis, showing clear evidence of intimal proliferation with eccentric narrowing (bottom). Reproduced from (22) with permission.

features of advanced plaques, including necrotic cores, fibrous caps, calcification, medial thinning and intraplaque haemorrhages.

Genetically modified porcine models. In genetic mini-pig models, atherosclerosis can be induced without the use of cholic acid, thereby avoiding its toxic inflammatory side effects (54). An example of a model system is the Yucatan mini-pig with liver-specific expression of D374Y, a gain-of-function mutation in human protein convertase PCSK9, which consistently downregulated LDL receptor levels and increased LDL concentrations following a high-fat diet. This led to a severe form of autosomal dominant hypercholesterolemia $(55,56)$, successfully inducing atherosclerosis in thoracic, abdominal, ilio-femoral and coronary arteries at 1 year of age. This model is applicable for validating equipment designed for human use, such as clinical scanners and intravascular devices. Another transgenic model is the LDLR knockout Yucatan mini-pigs, which demonstrated similar hypercholesterolemia and progression of atherosclerotic development. A high-fat diet led to the development of atherosclerotic lesions at 6-11 months (57).

Advantages and disadvantages of porcine models. The use of porcine models has the advantage of bearing close resemblance of cardiac anatomy and physiology to the human counterpart. LDL, as in humans, is the major circulating lipoprotein in plasma, except for apoliproprotein II deficiency in pigs. Another advantage is the highly defined genotypes, which enable the development of porcine models with multiple genetic alterations. The emergence of site-specific nucleases, including the clustered regularly interspaced short palindromic repeats (CRISPR)/Cas9 system, was a breakthrough that allowed multiple genes to be targeted at the same time by the expression of multiple sgRNAs together with the Cas9 nuclease. The CRISPR/Cas9 system allows pronuclear injection protocols with a high success rate (58), and only one animal cloning round is needed, reducing the time needed for breeding and the cost of production.

As with humans, pigs are susceptible to diet-induced hypercholesterolemia, but they require high dietary cholesterol, typically combined with cholic acid to block the conversion from cholesterol to bile $(59,60)$. The atherosclerotic lesions usually do not progress beyond the foam cell stage and the duration of atheroma formation is longer than that observed in mice. Combining the use of an atherogenic diet with artificial vascular injury is one of the methods to accelerate atherosclerosis development in pigs. First, normal pigs are fed with a high cholesterol diet and percutaneous intramural injection of cholesteryl esters and human oxLDL $(61,62)$. Two weeks later, vascular injury is produced by methods such as guidewire-induced injury, endovascular balloon inflation and partial vessel ligation (63). This method produces rapid atherosclerotic plaque development, thereby reducing the duration and cost of the experimental studies. The histopathology of atherosclerotic lesions are similar to humans, including their location and content (57). This model therefore provides a platform for the investigation of the disease complications, including plaque rupture, ischemic reperfusion injury, arterial thrombosis and restenosis after angioplasty (64-66), and explorations for therapeutic interventions such as drug-eluting stents (66).

The use of the porcine model as an in vivo validation of imaging tools is valuable, in contrast to the post mortem specimen and ex vivo model, which failed to produce satisfactory validation. Post-mortem specimens cannot imitate the dynamic cell components in atherosclerotic plaques, whereas ex vivo models do not demonstrate the pulsatile flow normally observed in elastic arteries, moving coronary arteries on a beating heart, irregular heart rhythms and the moving tissues surrounding the vessels. Initial validation is crucial for the development of intravascular imaging technique to guide therapy in symptomatic patients $(67,68)$. With the authentic human-like dimension and morphology of coronary arteries, pigs provide an ideal platform for the insertion of intravascular imaging tools, such as intravascular ultrasound (69) and near-infrared spectroscopy (70). Real-time imaging of tissues and cells in evolving atherosclerotic plaques is also possible.

Due to lack of sensitive and reliable biomarkers for monitoring disease progression, imaging tools are important in 
monitoring plaque evolution and the efficacy of therapeutic treatment. For non-invasive imaging with PET-CT, MRI or CT, high resolution imaging of large arteries in smaller animals is possible using dedicated and modified scan protocols. Porcine models are useful to establish the relationship between plaque size and system resolution, with similar extents of motion and artefacts compared to humans. The protocol of scan parameter can be used subsequently without the need of modification.

Another valuable use of the porcine model is drug development. In view of the close phylogenetic relationship and relevant atherosclerotic pathology observed in porcine systems $(71,72)$, drug testing is predictive for efficacy of drugs in humans compared to the mouse model. It can be used to guide the decision on endpoint of drug efficacy in clinical trials. Currently, there is no standard imaging endpoint that is capable of detecting all beneficial effects of pharmacological intervention $(73,74)$. Some drugs target lipid content reduction, which is potentially measurable using near-infrared spectroscopy (70). By contrast, other drugs that aim to reduce inflammation can be assessed by 18 fluorodeoxyglucose PET-CT techniques (75). Porcine models offer a test platform where both pathological examinations of atherosclerosis and evaluation with clinical imaging end point can be performed concurrently (71).

Nonetheless, the large size of pigs limits their widespread use. Recently, genetically engineered mini-pigs $(76,77)$ in which hyperlipidemia and consequently atherosclerosis were successfully induced, became available; they are cheaper to maintain compared to full-sized pigs. A close examination of its pathophysiological mechanisms revealed similarities with human atherosclerosis, as in the full-sized pigs, that are not observed in mouse models.

Non-human primate models. Non-human primate models bear closest similarities to humans compared to other species, in terms of phylogeny with $98 \%$ genetic material being identical.

Rhesus and cynomolgus monkeys. Complex atherosclerotic lesions in coronary arteries of Rhesus monkeys were successfully induced using a high fat, high cholesterol diet (57). The lesions demonstrated intimal thickening and increased density of vasa vasorum in the tunica media (78), which are features also observed in humans. The identification of regression of coronary atherosclerosis upon reversion to a low-fat diet was first established using this model system (79). This was associated with a lower cholesterol content within the lesions and a decrease in the number of foam cells as well as their lipid content. Cynomolgus monkeys have been used because of their higher sensitivity to a high-fat diet. When these animals were fed with $12.5 \%$ coconut oil and $12.5 \%$ of butter fat $(50,80)$, their plasma cholesterol level was twice as high as those of the Rhesus monkeys, associated with a higher number of lipid-loaded monocytes in the blood and skin xanthomata, as well as faster disease progression.

Advantages and disadvantages of primate models. The major advantage of using primates is that they have very similar cardiac anatomy and physiology compared to humans. Abnormal cardiovascular physiology in terms of lesion morphology, plaque vulnerability and development of spontaneous luminal thrombosis are observed in both species $(51,80-82)$. Primates bear similar susceptibility to atherosclerosis, with youngeraged animals being reasonably resistant to development of atherosclerosis, but have an increased risk of becoming susceptible with increasing age (83). Gender difference in the susceptibility of atherosclerosis have been demonstrated in these primate models, with a male preponderance to development of atherosclerosis following the introduction of a high-fat diet (84). High cholesterol diet greatly accelerated the development of atherosclerosis and frequently induced fatal MI in these primates (85). Conversely, disease regression upon low fat feeding was also evident, in keeping with clinical findings $(86,87)$. Finally, associations between psychosocial factors and atherosclerosis have similarly been established for these primate models (88). Taken together, these factors lead to a greater applicability of experimental data on the clinical scenario.

Despite bearing close resemblances to humans, primate models are less popular than the other types of model due to its difficulty in maintainance due to their large size, high cost, limited availability and the special facilities required for their accommodation. Secondly, a considerate length of time is needed to induce significant atherosclerosis. Thirdly, the ethical concern of experimenting with human-like primates limits their widespread use. Nevertheless, non-human primates are ideal for the development of reliable biomarker tools for risk stratification and monitoring of the effects of pharmacological interventions on disease progression.

\section{Concluding remarks}

Animal models have been extensively used to study the pathophysiology of cardiovascular disorders (89-106). There is no one single ideal animal model for all the diseases $(107,108)$. The general criteria for an appropriate animal model includes the size, docility, ease of breeding and housing, known genetic profile, analogies with humans and the cost associated. A smaller animal model, such as mouse and rabbit, generally provide valuable information on etiology and pathophysiology of atherosclerosis. Understanding of the risk factors and the natural history of atherosclerosis offer insights on disease prevention. On the other hand, larger animal models, such as porcine and non-human primates, are more reliable homologies with human disease. The advanced lesions developed share similar histological features with humans, from initial content of fatty streak to final advanced lesion of ulceration and thrombus formation. Their use is therefore more valuable for the development of disease management, such as analysing the utility imaging methods and assessing the efficacy of pharmacological intervention.

With the advancement in genetic technology, the development of mini-pigs is a favourable trade-off between human-like physiology compared to non-human primate; and ease of handling compared with small animal, with high resemblance to human cardiac anatomy, physiology, lipid metabolism and atherosclerotic pathophysiology. IT is expected to act as an important in vivo model, for developing sensitive biomarkers and validated imaging tools to predict plaque rupture, as the most important clinical event that cost life in atherosclerosis. 


\section{Acknowledgements}

GT was supported by a BBSRC Doctoral Training Award and thanks the Croucher Foundation of Hong Kong for the generous support of his clinical assistant professorship. YC is supported by the ESRC.

\section{References}

1. Nordestgaard BG, Chapman MJ, Humphries SE, Ginsberg HN, Masana L, Descamps OS, Wiklund O, Hegele RA, Raal FJ, Defesche JC, et al; European Atherosclerosis Society Consensus Panel: Familial hypercholesterolaemia is underdiagnosed and undertreated in the general population: guidance for clinicians to prevent coronary heart disease: consensus statement of the European Atherosclerosis Society. Eur Heart J 34: 3478-3490a, 2013.

2. Lim SS, Vos T,Flaxman AD, Danaei G, Shibuya K, Adair-RohaniH, Amann M, Anderson HR, Andrews KG, Aryee M, et al: A comparative risk assessment of burden of disease and injury attributable to 67 risk factors and risk factor clusters in 21 regions, 1990-2010: A systematic analysis for the Global Burden of Disease Study 2010. Lancet 380: 2224-2260, 2012.

3. Yusuf S, Hawken S, Ounpuu S, Dans T, Avezum A, Lanas F, McQueen M, Budaj A, Pais P, Varigos J, et al; INTERHEART Study Investigators: Effect of potentially modifiable risk factors associated with myocardial infarction in 52 countries (the INTERHEART study): Case-control study. Lancet 364: 937-952, 2004.

4. Steinberg D, Glass CK and Witztum JL: Evidence mandating earlier and more aggressive treatment of hypercholesterolemia. Circulation 118: 672-677, 2008.

5. Ma S, Tian XY, Zhang Y, Mu C, Shen H, Bismuth J, Pownall HJ, Huang $\mathrm{Y}$ and Wong WT: E-selectin-targeting delivery of microRNAs by microparticles ameliorates endothelial inflammation and atherosclerosis. Sci Rep 6: 22910, 2016.

6. Lee WH, Kim SH, Jeong EM, Choi YH, Kim DI, Lee BB, Cho YS, Kwon BS and Park JE: A novel chemokine, Leukotactin-1, induces chemotaxis, pro-atherogenic cytokines, and tissue factor expression in atherosclerosis. Atherosclerosis 161: 255-260, 2002.

7. Tabas I: 2016 Russell Ross Memorial Lecture in Vascular Biology: Molecular-Cellular Mechanisms in the Progression of Atherosclerosis. Arterioscler Thromb Vasc Biol. 2016 Dec 15 pii: ATVBAHA.116.308036. PMID: 27979856

8. Di Pietro N, Formoso G and Pandolfi A: Physiology and pathophysiology of oxLDL uptake by vascular wall cells in atherosclerosis. Vascul Pharmacol 84: 1-7, 2016.

9. Randolph GJ, Jakubzick C and Qu C: Antigen presentation by monocytes and monocyte-derived cells. Curr Opin Immunol 20 52-60, 2008

10. Gerthoffer WT: Mechanisms of vascular smooth muscle cell migration. : Circ Res 100: 607-621, 2007.

11. Zhao Y, Biswas SK, McNulty PH, Kozak M, Jun JY and Segar L: PDGF-induced vascular smooth muscle cell proliferation is associated with dysregulation of insulin receptor substrates. Am J Physiol Cell Physiol 300: C1375-C1385, 2011.

12. Shah PK: Mechanisms of plaque vulnerability and rupture. J Am Coll Cardiol. 41: 15S-22S, 2003.

13. Majesky MW: Developmental basis of vascular smooth muscle diversity. Arterioscler Thromb Vasc Biol 27: 1248-1258, 2007.

14. VanderLaan PA, Reardon CA and Getz GS: Site specificity of atherosclerosis: Site-selective responses to atherosclerotic modulators. Arterioscler Thromb Vasc Biol 24: 12-22, 2004.

15. Ley K, Miller YI and Hedrick CC: Monocyte and macrophage dynamics during atherogenesis. Arterioscler Thromb Vasc Biol 31: 1506-1516, 2011

16. Moore KJ and Tabas I: Macrophages in the pathogenesis of atherosclerosis. Cell 145: 341-355, 2011.

17. Baetta R and Corsini A: Role of polymorphonuclear neutrophils in atherosclerosis: Current state and future perspectives. Atherosclerosis 210: 1-13, 2010.

18. Weber C, Zernecke A and Libby P: The multifaceted contributions of leukocyte subsets to atherosclerosis: Lessons from mouse models. Nat Rev Immunol 8: 802-815, 2008.

19. Lahoute C, Herbin O, Mallat Z and Tedgui A: Adaptive immunity in atherosclerosis: Mechanisms and future therapeutic targets. Nat Rev Cardiol 8: 348-358, 2011.
20. Getz GS, Vanderlaan PA and Reardon CA: Natural killer $\mathrm{T}$ cells in lipoprotein metabolism and atherosclerosis. Thromb Haemost 106: 814-819, 2011.

21. Butcher M and Galkina E: Current views on the functions of interleukin-17A-producing cells in atherosclerosis. Thromb Haemost 106: 787-795, 2011.

22. Newby AC: Metalloproteinase expression in monocytes and macrophages and its relationship to atherosclerotic plaque instability. Arterioscler Thromb Vasc Biol 28: 2108-2114, 2008.

23. Tse G, Wong ST, Tse V, Lee YT, Lin HY and Yeo JM: Cardiac dynamics: alternans and arrhythmogenesis. J Arrhythm 32: 411-417, 2016.

24. Tse G, Wong ST, Tse V and Yeo JM: Depolarization vs. repolarization: What is the mechanism of ventricular arrhythmogenesis underlying sodium channel haploinsufficiency in mouse hearts? Acta Physiol (Oxf): Apr 16, 2016 (Epub ahead of print).

25. Tse G: (Tpeak - Tend)/QRS and (Tpeak - Tend)/(QT x QRS): Novel markers for predicting arrhythmic risk in the Brugada syndrome. Europace: Oct 5, 2016 (Epub ahead of print).

26. Tse G, Wong ST, Tse V and Yeo JM: Determination of action potential wavelength restitution in Scn5a/-mouse hearts modelling human Brugada syndrome. J Physiol (In press).

27. Tse G: Both transmural dispersion of repolarization and transmural dispersion of refractoriness are poor predictors of arrhythmogenicity: A role for the index of Cardiac Electrophysiological Balance (QT/QRS)? J Geriatr Cardiol (In press).

28. Tse G: Novel conduction-repolarization indices for the stratification of arrhythmic risk. J Geriatr Cardiol (In press).

29. Tse G, Wong ST, Tse V and Yeo JM: Variability in local action potential durations, dispersion of repolarization and wavelength restitution in aged wild-type and Scn5a/-mouse hearts modelling human Brugada syndrome. J Geriatr Cardiol (In press).

30. Hu Z, Chen Z, Wang Y, Jiang J, Tse G, Xu W, Ge J and Sun B: Effects of granulocyte colony-stimulating factor on rabbit carotid and swine heart models of chronic obliterative arterial disease. Mol Med Rep (In press).

31. Tse G, Yeo JM, Tse V, Kwan J and Sun B: Gap junction inhibition by heptanol increases ventricular arrhythmogenicity by reducing conduction velocity without affecting repolarization properties or myocardial refractoriness in Langendorff-perfused mouse hearts. Mol Med Rep 14: 4069-4074, 2016.

32. Tse G, Tse V and Yeo JM: Ventricular anti-arrhythmic effects of heptanol in hypokalaemic, Langendorff-perfused mouse hearts. Biomed Rep 4: 313-324, 2016.

33. Tse G, Tse V, Yeo JM and Sun B: Atrial anti-arrhythmic effects of heptanol in Langendorff-perfused mouse hearts. PLoS One 11: e0148858, 2016.

34. Tse G, Wong ST, Tse V and Yeo JM: Restitution analysis of alternans using dynamic pacing and its comparison with S1S2 restitution in heptanol-treated, hypokalaemic Langendorff-perfused mouse hearts. Biomed Rep 4: 673-680, 2016.

35. Tse G, Wong ST, Tse V and Yeo JM: Monophasic action potential recordings: Which is the recording electrode? J Basic Clin Physiol Pharmacol 27: 457-462, 2016.

36. Tse G, Lai ET, Yeo JM, Tse V and Wong SH: Mechanisms of electrical activation and conduction in the gastrointestinal system: Lessons from cardiac electrophysiology. Front Physiol 7: $182,2016$.

37. Tse G, Lai ET, Tse V and Yeo JM: Molecular and electrophysiological mechanisms underlying cardiac arrhythmogenesis in diabetes mellitus. J Diabetes Res 2016: 2848759, 2016.

38. Tse G, Lai ET, Yeo JM and Yan BP: Electrophysiological mechanisms of Bayés syndrome: Insights from clinical and mouse studies. Front Physiol 7: 188, 2016.

39. Tse G, Sun B, Wong ST, Tse V and Yeo JM: Anti-arrhythmic effects of hypercalcemia in hyperkalemic, Langendorff-perfused mouse hearts. Biomed Rep 5: 301-310, 2016.

40. Chen Z, Sun B, Tse G, Jiang J and Xu W: Reversibility of both sinus node dysfunction and reduced HCN4 mRNA expression level in an atrial tachycardia pacing model of tachycardia-bradycardia syndrome in rabbit hearts. Int J Clin Exp Pathol 9: 8526-8531, 2016

41. Tse G, Yeo JM, Chan YW, Lai ET and Yan BP: What is the arrhythmic substrate in viral myocarditis? Insights from clinical and animal studies. Front Physiol 7: 308, 2016.

42. Nordestgaard BG and Zilversmit DB: Large lipoproteins are excluded from the arterial wall in diabetic cholesterol-fed rabbits. J Lipid Res 29: 1491-1500, 1988. 
43. Kritchevsky D: Herman Award Lecture, 1992: Lipid nutrition - a personal perspective. Am J Clin Nutr 56: 730-734, 1992.

44. Spagnoli LG, Orlandi A, Mauriello A, Santeusanio G, de Angelis C, Lucreziotti R and Ramacci MT: Aging and atherosclerosis in the rabbit. 1. Distribution, prevalence and morphology of atherosclerotic lesions. Atherosclerosis 89: 11-24, 1991.

45. Bocan TM, Mueller SB, Mazur MJ, Uhlendorf PD, Brown EQ and Kieft KA: The relationship between the degree of dietary-induced hypercholesterolemia in the rabbit and atherosclerotic lesion formation. Atherosclerosis 102: 9-22, 1993.

46. Shiomi $\mathrm{M}$ and Ito T: The Watanabe heritable hyperlipidemic (WHHL) rabbit, its characteristics and history of development: A tribute to the late Dr. Yoshio Watanabe. Atherosclerosis 207: 1-7, 2009.

47. Buja LM, Kita T, Goldstein JL, Watanabe Y and Brown MS: Cellular pathology of progressive atherosclerosis in the WHHL rabbit. An animal model of familial hypercholesterolemia. Arteriosclerosis 3: 87-101, 1983.

48. Atkinson JB, Hoover RL, Berry KK and Swift LL: Cholesterol-fed heterozygous Watanabe heritable hyperlipidemic rabbits: A new model for atherosclerosis. Atherosclerosis 78: 123-136, 1989.

49. Shiomi M, Ito T, Shiraishi M and Watanabe Y: Inheritability of atherosclerosis and the role of lipoproteins as risk factors in the development of atherosclerosis in WHHL rabbits: Risk factors related to coronary atherosclerosis are different from those related to aortic atherosclerosis. Atherosclerosis 96: 43-52, 1992

50. Davis HR, Vesselinovitch D and Wissler RW: Reticuloendothelial system response to hyperlipidemia in rhesus and cynomolgus monkeys. J Leukoc Biol 36: 63-80, 1984.

51. Mott GE, Jackson EM, McMahan CA and McGill HC Jr: Dietary cholesterol and type of fat differentially affect cholesterol metabolism and atherosclerosis in baboons. J Nutr 122 1397-1406, 1992

52. Gerrity RG: The role of the monocyte in atherogenesis: I. Transition of blood-borne monocytes into foam cells in fatty lesions. Am J Pathol 103: 181-190, 1981.

53. Gerrity RG, Natarajan R, Nadler JL and Kimsey $T$ : Diabetes-induced accelerated atherosclerosis in swine. Diabetes 50: 1654-1665, 2001.

54. Civelek M, Manduchi E, Riley RJ, Stoeckert CJ Jr and Davies PF: Coronary artery endothelial transcriptome in vivo: Identification of endoplasmic reticulum stress and enhanced reactive oxygen species by gene connectivity network analysis. Circ Cardiovasc Genet 4: 243-252, 2011

55. Nakashima Y, Plump AS, Raines EW, Breslow JL and Ross R ApoE-deficient mice develop lesions of all phases of atherosclerosis throughout the arterial tree. Arterioscler Thromb 14: 133-140, 1994.

56. Getz GS and Reardon CA: Apoprotein E as a lipid transport and signaling protein in the blood, liver, and artery wall. J Lipid Res 50: S156-S161, 2009.

57. Williams JK, Armstrong ML and Heistad DD: Vasa vasorum in atherosclerotic coronary arteries: Responses to vasoactive stimuli and regression of atherosclerosis. Circ Res 62: 515-523, 1988.

58. Hai T, Teng F, Guo R, Li W and Zhou Q: One-step generation of knockout pigs by zygote injection of CRISPR/Cas system. Cell Res 24: 372-375, 2014.

59. Getz GS and Reardon CA: Animal models of atherosclerosis. Arterioscler Thromb Vasc Biol 32: 1104-1115, 2012.

60. Al-Mashhadi RH, Sørensen CB, Kragh PM, Christoffersen C, Mortensen MB, Tolbod LP, Thim T, Du Y, Li J, Liu Y, et al: Familial hypercholesterolemia and atherosclerosis in cloned minipigs created by DNA transposition of a human PCSK 9 gain-of-function mutant. Sci Transl Med 5: 166ra1, 2013.

61. Granada JF, Moreno PR, Burke AP, Schulz DG, Raizner AE and Kaluza GL: Endovascular needle injection of cholesteryl linoleate into the arterial wall produces complex vascular lesions identifiable by intravascular ultrasound: Early development in a porcine model of vulnerable plaque. Coron Artery Dis 16 217-224, 2005

62. Granada JF, Wallace-Bradley D, Win HK, Alviar CL, Builes A, Lev EI, Barrios R, Schulz DG, Raizner AE and Kaluza GL: In vivo plaque characterization using intravascular ultrasound-virtual histology in a porcine model of complex coronary lesions. Arterioscler Thromb Vasc Biol 27: 387-393, 2007.

63. Thim T, Hagensen MK, Drouet L, Bal Dit Sollier C, Bonneau M, Granada JF, Nielsen LB, Paaske WP, Bøtker HE and Falk E: Familial hypercholesterolaemic downsized pig with human-like coronary atherosclerosis: A model for preclinical studies. EuroIntervention 6: 261-268, 2010 .
64. Dansky HM, Charlton SA, Harper MM and Smith JD: T and B lymphocytes play a minor role in atherosclerotic plaque formation in the apolipoprotein E-deficient mouse. Proc Nat Acad Sci USA 94: 4642-4646, 1997.

65. Nakashima Y, Raines EW, Plump AS, Breslow JL and Ross R Upregulation of VCAM-1 and ICAM-1 at atherosclerosis-prone sites on the endothelium in the ApoE-deficient mouse. Arterioscler Thromb Vasc Biol 18: 842-851, 1998.

66. Iiyama K, Hajra L, Iiyama M, Li H, DiChiara M, Medoff BD and Cybulsky MI: Patterns of vascular cell adhesion molecule-1 and intercellular adhesion molecule-1 expression in rabbit and mouse atherosclerotic lesions and at sites predisposed to lesion formation. Circ Res 85: 199-207, 1999.

67. Fazio S, Babaev VR, Murray AB, Hasty AH, Carter KJ, Gleaves LA, Atkinson JB and Linton MF: Increased atherosclerosis in mice reconstituted with apolipoprotein $\mathrm{E}$ null macrophages. Proc Natl Acad Sci USA 94: 4647-4652, 1997.

68. Van Eck M, Herijgers N, Vidgeon-Hart M, Pearce NJ, Hoogerbrugge PM, Groot PH and Van Berkel TJ: Accelerated atherosclerosis in C57B1/6 mice transplanted with ApoE-deficient bone marrow. Atherosclerosis 150: 71-80, 2000.

69. Mazzone T and Reardon C: Expression of heterologous human apolipoprotein E by J774 macrophages enhances cholesterol efflux to HDL3. J Lipid Res 35: 1345-1353, 1994.

70. Strong JP and McGill HC Jr: Diet and experimental atherosclerosis in baboons. Am J Pathol 50: 669-690, 1967.

71. Kaplan JR, Manuck SB, Clarkson TB, Lusso FM and Taub DM: Social status, environment, and atherosclerosis in cynomolgus monkeys. Arteriosclerosis 2: 359-368, 1982

72. Thorngate FE, Rudel LL, Walzem RL and Williams DL: Low levels of extrahepatic nonmacrophage ApoE inhibit atherosclerosis without correcting hypercholesterolemia in ApoE-deficient mice. Arterioscler Thromb Vasc Biol 20 1939-1945, 2000.

73. Linton MF and Fazio S: Macrophages, lipoprotein metabolism, and atherosclerosis: Insights from murine bone marrow transplantation studies. Curr Opin Lipidol 10: 97-105, 1999.

74. Yang X, Peterson L, Thieringer R, Deignan JL, Wang X, Zhu J, Wang S, Zhong H, Stepaniants S, Beaulaurier J, et al: Identification and validation of genes affecting aortic lesions in mice. J Clin Invest 120: 2414-2422, 2010.

75. Barcat D, Amadio A, Palos-Pinto A, Daret D, Benlian P, Darmon M and Bérard AM: Combined hyperlipidemia/hyperalphalipoproteinemia associated with premature spontaneous atherosclerosis in mice lacking hepatic lipase and low density lipoprotein receptor. Atherosclerosis 188: 347-355, 2006.

76. Davis BT, Wang XJ, Rohret JA, Struzynski JT, Merricks EP, Bellinger DA, Rohret FA, Nichols TC and Rogers CS: Targeted disruption of LDLR causes hypercholesterolemia and atherosclerosis in Yucatan miniature pigs. PLoS One 9: e93457, 2014.

77. Agarwala A, Billheimer J and Rader DJ: Mighty minipig in fight against cardiovascular disease. Sci Transl Med 5: 166fs1, 2013.

78. Heistad DD and Armstrong ML: Blood flow through vasa vasorum of coronary arteries in atherosclerotic monkeys. Arteriosclerosis 6: 326-331, 1986.

79. Armstrong ML and Megan MB: Lipid depletion in atheromatous coronary arteries in rhesus monkeys after regression diets. Circ Res 30: 675-680, 1972.

80. Davis HR, Vesselinovitch D and Wissler RW: Histochemical detection and quantification of macrophages in rhesus and cynomolgus monkey atherosclerotic lesions. J Histochem Cytochem 32: 1319-1327, 1984.

81. Wolfe MS, Sawyer JK, Morgan TM, Bullock BC and Rudel LL: Dietary polyunsaturated fat decreases coronary artery atherosclerosis in a pediatric-aged population of African green monkeys. Arterioscler Thromb 14: 587-597, 1994.

82. Vesselinovitch D, Getz GS, Hughes RH and Wissler RW: Atherosclerosis in the rhesus monkey fed three food fats. Atherosclerosis 20: 303-321, 1974

83. Bullock BC, Clarkson TB, Lehner ND, Lofland HB Jr and St Clair RW: Atherosclerosis in Cebus albifrons monkeys. Clinical and pathologic studies. Exp Mol Pathol 10: 39-62, 1969.

84. Clarkson TB, Koritnik DR, Weingand KW and Miller LC: Nonhuman primate models of atherosclerosis: Potential for the study of diabetes mellitus and hyperinsulinemia. Metabolism 34 (Suppl 1): 51-59, 1985

85. Taylor CB, Cox GF, Hall-Taylor BJ and Nelson LG: Atherosclerosis in areas of vascular injury in monkeys with mild hypercholesterolemia. Circulation 10: 613, 1954. 
86. Clarkson TB, Lehner NDM, Wagner WD, St Clair RW, Bond MG and Bullock BC: A study of atherosclerosis regression in Macaca mulatta. I. Design of experiment and lesion induction. Exp Mol Pathol 30: 360-385, 1979

87. Clarkson TB, Bond MG, Bullock BC, McLaughlin KJ and Sawyer JK: A study of atherosclerosis regression in Macaca mulatta. V. Changes in abdominal aorta and carotid and coronary arteries from animals with atherosclerosis induced for 38 months and then regressed for 24 or 48 months at plasma cholesterol concentrations of 300 or $200 \mathrm{mg} / \mathrm{dl}$. Exp Mol Pathol 41: 96-118, 1984.

88. Kaplan JR and Manuck SB: Status, stress, and atherosclerosis: The role of environment and individual behavior. Ann N Y Acad Sci 896: 145-161, 1999.

89. Choy L, Yeo JM, Tse V, Chan SP and Tse G: Cardiac disease and arrhythmogenesis: Mechanistic insights from mouse models. Int J Cardiol Heart Vasc 12: 1-10, 2016.

90. Tse G and Yan BP: Novel arrhythmic risk markers incorporating QRS dispersion: QRSd x (Tpeak - Tend )/QRS and QRSd x (Tpeak - Tend )/(QT x QRS). Ann Noninvasive Electrocardiol: Aug 18, 2016 (Epub ahead of print).

91. Tse G and Yan BP: Electrophysiological mechanisms of long and short QT syndromes: insights from mouse models. IJC Heart \& Vasculature, 2016

92. Tse G, Lai ETH, Lee APW, Yan BP and Wong SH: Electrophysiological mechanisms of gastrointestinal arrhythmogenesis: Lessons from the heart. Front Physiol 7: 230, 2016.

93. Tse G and Yan BP: Traditional and novel electrocardiographic conduction and repolarization markers of sudden cardiac death Europace: Oct 4, 2016 (Epub ahead of print).

94. Tse G, Yan BP, Chan YW, Tian XY and Huang Y: Reactive oxygen species, endoplasmic reticulum stress and mitochondrial dysfunction: The link with cardiac arrhythmogenesis. Front Physiol 7: 313, 2016.

95. Tse G, Wong ST, Tse V and Yeo JM: Schrödinger's cat in cardiac electrophysiology: Quinidine both increases and decreases left ventricular endocardial action potential durations in Langendorff-perfused mouse hearts. Acta Physiol (Oxf), 2016.

96. Sun B, Chen Z, Gu J, et al: Tight junction proteins and gap junction proteins play important roles in high fat dietary atherosclerosis pathogenesis. Int J Clin Exp Pathol 9: 7969-7976, 2016.

97. Chen-Izu Y, Shaw RM, Pitt GS, Yarov-Yarovoy V, Sack JT, Abriel H, Aldrich RW, Belardinelli L, Cannell MB, Catterall WA, et al: $\mathrm{Na}^{+}$channel function, regulation, structure, trafficking and sequestration. J Physiol 593: 1347-1360, 2015.

98. Tse G, Ali A, Prasad SK, Vassiliou V and Raphael CE: Atypical case of post-partum cardiomyopathy: an overlap syndrome with arrhythmogenic right ventricular cardiomyopathy? BJR Case Rep 1: 20150182, 2015

99. Tse G, Ali A, Alpendurada F, Prasad S, Raphael CE and Vassiliou V: Tuberculous constrictive pericarditis. Res Cardiovasc Med 4: e29614, 2015.
100. Tse G and Yeo JM: Conduction abnormalities and ventricular arrhythmogenesis: The roles of sodium channels and gap junctions. Int J Cardiol Heart Vasc 9: 75-82, 2015.

101. Tse G: Mechanisms of cardiac arrhythmias. J Arrhythm 32: 75-81, 2016.

102. Tse G, Hothi SS, Grace AA and Huang CL: Ventricular arrhythmogenesis following slowed conduction in heptanol-treated, Langendorff-perfused mouse hearts. J Physiol Sci 62: 79-92, 2012 .

103. Yeo JM, Tse V, Kung J, Lin HY, Lee YT, Kwan J, Yan BP and Tse G: Isolated heart models for studying cardiac electrophysiology: a historical perspective and recent advances. J Basic Clin Physiol Pharmacol (In press).

104. Tse, G, Liu T, Li KH, Laxton, V, Wong A, Chan YW, Keung W, Chan C and Li RA: (2016) Molecular and electrophysiological mechanisms of tachycardia-bradycardia syndrome. Int J Mol Med (In press).

105. Fu H, Li G, Liu C, Li J, Cheng L, Yang W, Tse G, Zhao J and Liu T: Probucol prevents atrial ion channel remodeling in an alloxan-induced diabetes rabbit model. Oncotarget: Nov 14 2016 (Epub ahead of print).

106. Tse G, Liu T, Li KH, Laxton V, Chan YW, Keung W, Li RA and Yan BP: Electrophysiological mechanisms of Brugada syndrome: insights from pre-clinical and clinical studies. Front Physiol 7: 467, 2016.

107. Wong P, Laxton V, Srivastava S, Chan YW and Tse G: The role of gap junctions in inflammatory and neoplastic disorders. Int J Mol Med (In press).

108. Wong P, Tan T, Chan C, Laxton V, Chan YWF, Liu T, Wong WT and Tse G: The role of connexins in wound healing and erpair: Novel therapeutic approaches. Front. Physiol 7: 596, 2016. 